Max-Planck-Institut für demografische Forschung

Max Planck Institute for Demographic Research

Doberaner Strasse 114 - D-18057 Rostock · GERMANY

Tel +49 (0) 3812081 - 0; Fax +49 (0) 3812081 - 202;

http://www.demogr.mpg.de

MPIDR WORKING PAPER WP 2001-015

JUNE 2001

Regional Social Contexts and Individual

Fertility Decisions:

A Multilevel Analysis of First and Second

Births in Western Germany

Karsten Hank (hank@ demogr.mpg.de)

This working paper has been approved for release by: Hans-Peter Kohler (kohler@ demogr.mpg.de) Head of the Research Group on Social Dynamics and Fertility

C) Copyright is held by the authors.

Working papers of the Max Planck Institute for Demographic Research receive only limited review. Views or opinions expressed in working papers are attributable to the authors and do not necessarily reflect those of the Institute. 


\title{
Regional Social Contexts and Individual Fertility Decisions: A Multilevel Analysis of First and Second Births in Western Germany
}

\author{
Karsten Hank ${ }^{\star}$
}

\begin{abstract}
In this paper, a multilevel approach is used to investigate whether and how regional social contexts influence first and second birth probabilities of women living in western Germany during the 1980s and 1990s. In the theoretical part it is argued that regional opportunity structures as well as local patterns of social interaction and culture may translate into parameters that directly affect individual behaviour. Individual level data from the German Socio-Economic Panel (GSOEP) are then linked with a set of regional indicators to estimate multilevel discrete-time logit models for the transition to the first and second child. The empirical analysis provides no evidence that the distinct fertility differences observed at the regional level are due to autonomous contextual effects. It is rather suggested that most of the observed regional variation may be due to differences in the spatial distribution of individual characteristics.
\end{abstract}

Keywords: multilevel analysis, fertility, Germany

\footnotetext{
* The views expressed in this paper are the author's views and do not necessarily reflect those of the Max Planck Institute for Demographic Research.

I am greatly indebted to Johannes Huinink and Hans-Peter Kohler for many helpful comments and suggestions. I would also like to thank Francesco C. Billari for his advice concerning the statistical model applied here, and Øystein Kravdal for comments on an earlier version of this paper. Last not least, I am grateful to the participants of several workshops and conferences for lively discussions.

Author's correspondence address: Max Planck Institute for Demographic Research, Doberaner Str. 114, 18057 Rostock, Germany. Telephone: +49-381-2081-163. Fax: +49-381-2081-463. Email: hank@demogr.mpg.de.
} 


\section{Introduction}

Distinct regional diversity in reproductive behaviour could be observed before, during, and after the historical fertility transition in all European countries (see Coale and Watkins 1986 for an overview). Even after Europe's second demographic transition (van de Kaa 1987), substantial regional variation in fertility levels has continued to exist within contemporary western low-fertility societies (e.g., Brunetta and Rotondi 1991, Höpflinger 1983, Kutzenberger and Fürst 1983, Noin and Chauviré 1991). In postunification Germany, however, researchers' attention has been attracted mainly by the rapid fertility decline in eastern Germany and by the question, whether fertility levels in East and West will converge over time (e.g., Conrad et al. 1996). This has often caused neglect of different family and fertility patterns across regions, which reach far more back in time than those currently observed between the 'old' and the 'new' Länder of the Federal Republic (see Kopp 2000 for an exception). In a recent review of regional fertility differences in western Germany, Hank (2001) finds longstanding geographic patterns of high- and low-fertility areas that have remained basically unchanged by the general fertility decline of the late 1960s and early 1970s. Consistent with results of earlier analyses, population density, family migration, and the occupational structure are found to be closely associated with regional total fertility rates in the 1990s. Little is known, however, about the mechanisms that link such local structural parameters to individual childbearing decisions.

Theoretically as well as empirically, the multilevel approach provides an appropriate tool to bridge the micro-macro gap (e.g., Courgeau and Baccaini 1998, DiPrete and Forristal 1994). The bulk of the demographic literature, however, is either 
micro or macro in orientation, and contextual analyses of reproductive behaviour so far have mainly focussed on developing countries (e.g., Entwisle et al. 1989, Hirschman and Guest 1990). In the present study, a multilevel perspective is taken to investigate whether and how regional social contexts influence first and second birth probabilities of women living in western Germany during the period 1984 to 1995 . For the empirical analysis, individual level data from the German Socio-Economic Panel (GSOEP) are linked with an exceptionally rich set of regional indicators provided by the Federal Office for Building and Regional Planning (BBR).

The paper is organised as follows: Section 2 deals with conceptual issues and challenges to contextual analyses. Section 3 discusses, how regional contexts may operate on individual fertility behaviour. The data, variables, and statistical methods used in this study are described in Section 4. Multilevel discrete-time logit models for the transition to the first and the second child are then estimated in Section 5 . Conclusions and perspectives for future research are presented in Section 6.

\section{Conceptual issues and challenges to contextual analyses}

The relationship between the 'micro' and the 'macro' is one of the classic issues in the social sciences (e.g., Alexander et al. 1987, Huber 1991). It is generally argued that social development is characterised by the dialectic relationship between individual action and social structure (e.g., Erbring and Young 1979). While the individual's scope of action is on the one hand determined by a set of given social and economic opportunities and constraints, a context's social and economic properties are simultaneously influenced by the behaviour of its individual members. From the 
viewpoint of methodological individualism, macro-social contexts can therefore be treated as the unintended result of purposive individual action (e.g., Coleman 1990, Esser 1988). Since the present study incorporates a relatively short period of time, though, it is reasonable to treat the regional social context as exogenous to the individual actor and her fertility decisions (Entwisle 1991: 282).

Analyses of data from different aggregation levels at one single common level face several serious conceptual problems. The most prominent one is the ecological fallacy, i.e. the interpretation of aggregate data outcomes at the individual level (see Alker 1969 for an extensive typology). Moreover, empirical manifestations of contextual effects depend on numerous prerequisites (Iversen 1991: 4ff.) and the additional explanatory power of contextual variables in empirical analyses often turns out to be rather small (e.g., DiPrete and Forristal 1994: 348). The implementation of contextual variables in empirical investigations of individual decision-making has also been questioned on more general methodological grounds (e.g., Hauser 1974; for a recent review see Ginther et al. 2000). One of the main arguments in this discussion is the assertion that statistically significant effects of macro level characteristics are merely the result of an underspecification at the individual level. To avoid this “contextual fallacy”, Hauser (1974: 374) demands a thorough consideration of particularly two issues, namely, the meaning of the contextual effect, and explicit selection on the dependent variable.

Many studies do not sufficiently lay out the social mechanisms that shall be responsible for the transfer between contextual properties and individual behaviour. Erbring and Young (1979: 400ff.) describe such unsatisfying formulations and interpretations of contextual mechanisms as 'social telepathy' or 'common fate'. There 
are, however, a number of interchange hypotheses that lend themselves to explain how contextual properties might translate into parameters that directly affect individual behaviour (e.g., Esser 1988, Falter 1978):

The identification hypothesis stresses the individual's orientation towards regionally specific social norms and cultural traditions. Closely related to this is the social interaction hypothesis, where context effects are assumed to be the result of direct or indirect interaction processes. While the former hypothesis also refers to larger spatial units, the latter should rather be relevant for the analysis of smaller areas only, such as neighbourhoods, boroughs, etc. The regionally different distribution of opportunities, such as the provision of infrastructure, for example, is the core of the opportunity structure hypothesis.

A similar set of hypotheses is suggested by Jencks and Mayer (1990: 113), who distinguish between epidemic models, collective socialisation models, and institutional models of neighbourhood effects. Nauck (1995: 95ff.) stresses the role of the "meso level' as a link between macro-social structures and micro-demographic behaviour. This intermediate level is conceptualised by Nauck as regional social contexts, which may affect individual behaviour in many different ways, e.g. as opportunity structures, as places of social control and reproduction of cultural patterns, as objects of identification, or as destination of selective migration.

The latter aspect points to the self-selection or 'reflection' problem, i.e. the potential endogeneity of contextual effects (e.g., Evans et al. 1992, Manski 1993). In the presence of selection processes, statistical controls for individual variables would not prevent finding a contextual effect, although it would be hardly possible to identify whether the context is actually influencing the individual or merely reflecting the 
average characteristics of the community. It is beyond the scope of the present paper and must be left to future research to fully account for this issue. However, a partial solution of the problem is a better understanding of the underlying mechanisms through which regional characteristics affect individual behaviour. Therefore the relationship between regional opportunity structures as well as local patterns of social interaction and culture on one hand, and individual fertility on the other, will be thoroughly discussed in the next sections.

\section{How contexts operate on individual behaviour}

\section{$\underline{3.1 \text { Regional opportunity structures and fertility decisions }}$}

Individuals not only behave according to their own characteristics, but also according to the constraints imposed by the living conditions that are particular to the region they live in (e.g., Courgeau and Baccaini 1998). One of the main determinants of these living conditions are local opportunity structures. With regard to fertility behaviour, they may be defined mainly by economic opportunities and constraints that are linked to childbearing and its proximate determinants, and the local demography, which affects the costs for engaging in a particular behaviour (see Billy and Moore 1992: 980). Moreover, Huinink and Wagner (1989: 676) distinguish between opportunity structures that are relevant for the socialisation of children and such influencing an individual's disposition towards family formation.

The general opportunity structure of an individual's place of residence should be

reflected by the degree of urbanisation. Andorka (1978), for instance, argues that urbanisation has created an inappropriate environment for rearing up children, e.g. 
regarding housing conditions. Cities moreover provide a social, economic, and cultural infrastructure that offers more alternatives to family formation than rural areas (e.g., Huinink and Wagner 1989).

More specifically, the local labour market structure should be highly relevant. Particularly the relationship between fertility and women's labour force participation has been widely discussed in demography, both at the individual and at the aggregate level (see Brewster and Rindfuss 2000 for a recent review). An individual woman's propensity to be engaged in market work is supposed to be positively influenced by the labour force participation of others, which is expected to contribute to a greater acceptance of gainful employment as a role model for women. It has generally been argued that this would lead to a reduction in fertility, mainly due to the increasing opportunity costs of childbearing in terms of foregone wages and the incompatibility of the mother and worker role. In recent years, however, the negative relationship between fertility and women's employment has apparently reversed in some industrialised countries. This indicates that there are places where women have found ways to combine work and childrearing, while in others they have not (Brewster and Rindfuss 2000: 279).

The availability of childcare plays a crucial role for this and therefore becomes a central part of a region's opportunity structure (e.g., Kravdal 1996, Kreyenfeld and Hank 2000). The public provision of day care is an important module for establishing an unbroken care arrangement, which is necessary to enable mothers to participate in the labour force. Thus, Stolzenberg and Waite (1984: 158) argue that "the greater the availability of childcare in a local area, the smaller the constraints of children on the market activity of wives who live there." In western Germany, however, the lack of 
adequate childcare remains a major institutional barrier to role compatibility (Hank and Kreyenfeld 2001, Kreyenfeld and Hank 2000). Still, "when women participate actively in the local labor market, it may become more influenced by and adapted to women. This, in turn, may provide each individual mother with better opportunities for finding a job after birth that is reasonably compatible with her family responsibilities and hence lowers childbearing costs" (Kravdal 1996: 204). Along the same line, Stolzenberg and Waite (1984) suggest that the effect of children on their mother's labour force participation can be treated as a function not only of the cost and availability of childcare, but also of the convenience of jobs for working mothers in their region of residence.

The occupational structure of a region furthermore decides upon the availability of qualified jobs. Since employment in the tertiary sector offers career opportunities especially for women (e.g., Blossfeld 1987: 114), the opportunity costs of childbearing should be comparatively high in areas with a prevalence of white-collar jobs, particularly in the absence of sufficient childcare.

The effect of the regional unemployment rate is less clearly predictable (e.g., De Cooman et al. 1987: 244). If the unemployment rate is treated as an indicator of the quantity of available jobs within reach, the opportunity costs involved with giving up or reducing market work for starting a family should be high in case of a low unemployment rate. Women's labour market activity should then be high and fertility should be low, particularly if at the same time a sufficient number of qualified jobs is available. A low unemployment rate, however, may also lead to an increase in a woman's propensity to become a mother (e.g., Hoem 2000: Section 5). The local labour market situation might well be considered as an indicator of a community's socio- 
economic status and the economic situation in general. If this is perceived as good, a woman (or couple, respectively) might be more likely to view a child as 'affordable' and therefore decide to have one.

At the end of this section, one should keep in mind that individuals with a high preference for children should tend to move into regions with opportunity structures that are favourable for the formation of a family and the socialisation of children (and vice versa). Thus, selective migration may have a positive feedback effect on already existing opportunity structures and is likely to increase differences in regional fertility levels.

\section{$\underline{3.2 \text { Social interactions, cultural milieus, and individual fertility behaviour }}$}

Social structure and culture are often assumed to operate on individuals through various intermediate groups (e.g., Campbell and Alexander 1965). These may either serve as channels for innovative interpersonal communication, facilitating the flow of information, or as conservative cultural forces, encouraging adherence to behavioural norms. Using the language of Montgomery and Casterline (1996), the former can be called social learning, while the latter can be described as social influence.

With regard to social learning, Bongaarts and Watkins (1996) distinguish analytically between the exchange of information and ideas on one hand, and the joint evaluation of their meaning in a particular (local) context on the other. In industrialised countries, particularly questions like 'Why should one have children at all, and if so, how many?', 'What about the availability, affordability, and quality of day care in the region of residence?', or 'Are family formation and labour force participation compatible?', should be the subject of fertility related processes of social learning. 
These issues are discussed directly by and in groups that are defined by spatial or social proximity, where the content of an individual's social network is the product of her individual preferences and "associational opportunities and constraints imposed by the neighborhood social context." (Huckfeldt 1983: 667) Even in the times of mass media and modern means of communication (Westoff 1999), community norms and direct personal communication remain highly influential for the development of an individual's attitudes towards questions such as 'Does it harm my child if I return to paid work and leave it in a day care centre too early?', or 'Is it better for a child's development if it has siblings?'. And if the availability of adequate day care or job opportunities for mothers on the regional labour market are considered, the experience of locals should be the prime source of information, too.

Moreover, regional social contexts may be viewed as 'culturally normative milieus' (Nauck 1995), where social control forces individuals to conform to the behavioural expectations of others. Social control presumably works at a small-scale spatial level only and should be facilitated in areas with a homogeneous population, where the individual does not have many possibilities to retreat (e.g., Blalock 1984: 358). Similar holds, if differences in cultural and normative patterns between larger spatial units are considered. The reproduction of such patterns through the regionally specific socialisation of individuals is therefore likely to be more 'successful' in remote rural areas than in urban conurbations.

Independent from any kind of social control or direct social influence, an area may finally become a 'place of identification' (Nauck 1995), where individuals are assumed to anticipate the adequacy of a certain behaviour in the specific social context they live in. Hammel (1990: 457, 467) calls this "anticipation of $[\ldots]$ cultural 
evaluation" and develops a notion of culture as "an intensely evaluative cloud of comments", which provides the normative and interpretative rules, according to which individuals consider their fertility decisions.

The socio-cultural dimension of the regional context, which has been discussed here, is difficult to tackle empirically. Nevertheless, in their interpretation of contextual effects on individual (fertility) behaviour, researchers should always be aware of the existence and the potential relevance of local patterns of social interaction and culture.

\section{Empirical procedure}

\section{$\underline{4.1 \text { Data and variables }}$}

\subsubsection{Data sources, choice of the regional context, selection of the sample}

The individual level data used in this paper were made available by the German SocioEconomic Panel Study (GSOEP) at the German Institute for Economic Research (DIW Berlin) (see Wagner et al. 1993 for a description of the data set). This longitudinal micro-database provides socio-economic information on currently more than 7,000 households (including an oversample of foreign-headed households) and 14,000 individuals in eastern and western Germany. The survey was started in the western states of Germany and is conducted annually since 1984.

Just recently it has been made possible to link all waves of the GSOEP with detailed information on the respondents place of residence in any given year of the study period. The so called 'GSOEP-Geocode' consists of regional indicators provided by the Federal Office for Building and Regional Planning (BBR). They refer to so 
called Raumordnungsregionen, i.e. functional-spatial units defined by the BBR for the analysis of regional disparities and developments. The data cover such fields as population development, social and economic structure, and the provision of various kinds of infrastructure. Since the boundaries of the Raumordnungsregionen have been newly defined in 1996, a longitudinal analysis is only possible for periods before or after that year (see BBR 1999). In this paper, information on the 75 western German Raumordnungsregionen for the years 1984 to 1995 is used. ${ }^{1}$

When the choice of context is made, the analyst needs to find a compromise between what is theoretically desirable and what can be translated into empirical practice. For reasons of data availability, rather highly aggregated Raumordnungsregionen are chosen as a spatial unit for the present study. As a consequence of the relatively great heterogeneity within the Raumordnungsregionen, it is not possible to address the potential effect of local patterns of social interaction and culture on the individual's fertility behaviour in a sensible manner (see Hammel 1990: 467ff.). The opportunity structure hypothesis, on the other hand, can be approached straightforwardly. The use of Raumordnungsregionen may even facilitate the substantive interpretation of possible aggregate level effects, since in many instances the scope of regional opportunity structures can be assumed to reach clearly beyond the individual's immediate place of residence. However, if Raumordnungsregionen instead

\footnotetext{
${ }^{1}$ Individual behaviour can be influenced by lagged as well as by contemporaneous contextual effects. The present analysis, however, considers only the impact of the individual's current social context, assuming instantaneous effects that negate possible prior influences. Huinink and Wagner (1989: 673) label this assumption 'adaptation hypothesis', as opposed to the 'socialisation hypothesis', where an individual's behaviour is assumed to be independent of the living conditions in her current region of residence but to be influenced by her region of origin only.
} 
of districts or municipalities are used as a spatial unit for the analysis, there is less variation between the separate regional contexts. Some differences that are measurable between smaller geographical entities are then likely to be balanced out.

Only respondents from the two original GSOEP subsamples are included in the analysis, i.e. western Germans and foreigners from Greece, Italy, Spain, Turkey, and former Yugoslavia, who already lived in Germany in 1984. The sample for the analysis of first births consists of 2,474 women, who are observed from age 20 onwards, unless this age was reached before the first year of observation. The upper age limit is 35 years. Since each individual is allowed to contribute multiple observations (see Section 4.2.2), this leads to 10,451 individual records, nested within 75 Raumordnungsregionen. The number of observed first births in the period 1984 to 1995 is 836 . For the analysis of the transition to the second child, information on 1,316 mothers aged 25 to 40 is used. The observation begins after the birth of the first child, or at the beginning of the study period, if the first birth occurred before that. This results in 4,867 individual records and 532 observed second births. Further descriptive sample statistics are displayed in Table 1.

[Table 1 about here]

\subsubsection{Description of the variables}

- Dependent variable

The individual-level binary dependent variable equals one in case of the occurrence of a first birth (second birth, respectively) within a one-year interval in the period 1984 to 1995. 
- Individual characteristics (control variables)

Since a non-linear effect of age is assumed, the woman's age and age squared are entered into the regression. For the analysis of second births, the mother's age at first birth (time-constant variable) is considered as well. ${ }^{2}$

Education is treated as a time-varying covariate, measured by a set of binary variables, indicating the respondent's highest educational degree at the time of the survey in each year. It is distinguished between being in education, having no degree, a vocational degree (reference category), or a university degree.

Assuming a positive correlation between a woman's marital status and her propensity to give birth, a time-varying binary variable indicating whether the woman is married at the time of the interview enters the equation.

Finally, to control for possible differences in the fertility behaviour of native Germans and foreigners, a time-constant binary variable indicating whether the respondent belongs to subsample B (immigrants from Greece, Italy, Spain, Turkey, and former Yugoslavia) of the GSOEP is included.

- Regional characteristics

A region's degree of urbanisation is accounted for by a set of three time-constant binary variables. Following the regional typology suggested by the Federal Office for Building and Regional Planning (see BBR 1999: 2), agglomerations (reference category), urbanised areas, and rural areas are distinguished.

\footnotetext{
${ }^{2}$ Models using age categories and the duration since first birth are a common alternative to the specification chosen here. For the analytic purpose of this study, both approaches are equally suitable.
} 
The local day-care provision rate is measured by the number of available slots in Kindergarten per 1000 children aged 3 to 6 . This information is taken from the DJI Regionaldatenbank, which includes information on the provision of public day-care at the district (Kreis) level. ${ }^{3}$ The Kreis level data are then aggregated to fit the respective Raumordnungsregion. Since regional childcare provision rates are available for the years 1986 and 1994 only, the observation period is divided into two parts, lasting from 1984 to 1989 , and from 1990 to 1995 , respectively. While the variable is assumed to be time-constant within each of the two periods, it may change its value between the first and the second part of the observation period.

The local labour market structure is represented here by three time varying variables: the share of employees in the tertiary sector, the regional unemployment rate, and the labour force participation of women. Note that when calculating the female labour force participation rate, only women liable to social security contributions were considered.

\subsection{Methods}

The data used in this study have two characteristics that require particular attention. First, individuals are nested within regional contexts, hence a multilevel model is in need. Secondly, since the data are observed annually, a discrete-time model is applied.

\subsubsection{The multilevel model}

Several statistical problems rule out the application of traditional single-level regression models to the analysis of multilevel data (see Hox and Kreft 1994 for a brief overview).

\footnotetext{
${ }^{3}$ See $h t t p: / / w w w . d j i . d e / 2 \_r d b / d e f a u l t . h t m$ for more information.
} 
Clustering of individuals within the same context results in a hierarchically structured data set and is likely to cause dependency among observations. Ordinarily least squares (OLS) models applied to such data can produce inefficient estimates of the parameters and downwardly biased estimates of their standard errors, because the assumption of independent disturbances - on which OLS is based - is critically violated (see Moulton 1990 for details).

Random coefficient models account for hierarchical data structures. In these models, coefficients may be fixed or random, where the choice between the two alternatives can be made separately for each coefficient in the equation (Hox and Kreft 1994: 289f.). In the analysis performed here, all regression coefficients other than the intercept are constrained to be fixed across the regional units. The equation for this random intercept model is

$$
y_{i j}=b_{0}+b_{1} x_{i j}+\left(u_{0 j}+\varepsilon_{i j}\right)
$$

where $y_{i j}$ represents the outcome of the dependent variable $y$ for observation $i$ within context $j$, while $x_{i j}$ is the individual level explanatory variable of the same observation. The random intercept's fixed component $b_{0}$ and the slope $b_{1}$ are the parameters of the equation. The error term (in parentheses) is more complex than in traditional regression equations, since it includes not only the micro error $\varepsilon_{i j}$, but also the macro error $u_{0 j}$. The latter indicates that the intercept may vary over contexts, i.e. $u_{0 j}$ measures the deviation of each context from $b_{0}$ (between-context variance). It captures otherwise unobserved regional effects and accounts for the correlation between individuals nested within the same context. All $\varepsilon_{i j}$ are assumed to be independent of each other with the expectation zero and the variance $\sigma_{\varepsilon}^{2}$. The macro level disturbances 
$u_{0 j}$ are independent of the individual level disturbances, have the expectation zero and the variance $\sigma_{u}^{2}$. If the $u_{0 j}$ turn out to be statistically significant from zero, context effects are present (e.g., Kreft and de Leeuw 1998: Chapter 3.4).

Multilevel generalised linear models (GLIM) can be used to overcome some of the shortcomings of simple random coefficient models, such as the underlying assumption of a normal error distribution. Hierarchical GLIM therefore allow the application of multilevel logistic regression models for the analysis of discrete dependent variables (see Guo and Zhao 2000 for an overview). The two-level model for a binary response variable is conceptually equivalent to equation [1]. The probability of the binary outcome to be one is defined as $p_{i j}=\operatorname{Pr}\left(y_{i j}=1\right)$, where $p_{i j}$ is modeled using a logit link function. With the standard assumption that $y_{i j}$ has a Bernoulli distribution, the multilevel model can be written as

$$
\log \left[p_{i j} /\left(1-p_{i j}\right)\right]=b_{0}+b_{1} x_{i j}+u_{0 j}
$$

where the same assumptions as in the case of multilevel linear models apply to $u_{0 j}$, i.e. the random effect is assumed to be normally distributed, with the expected value 0 and the variance $\sigma_{u}^{2}$. See Guo and Zhao (2000: 447) for a latent variable conceptualisation of this model.

\subsubsection{The discrete-time logit model}

Most methods developed for the analysis of event histories require that time is measured as a continuous variable. In this study, however, annual information on the respondent and her place of residence is used. Since these data cannot be treated as if they were continuous, a discrete-time model is applied here (e.g., Allison 1982, Yamaguchi 1991). 
The setup for discrete-time models is much like that for the case of continuous time, except for the assumption that time can only take positive integer values. It is supposed that a sample of $n$ independent individuals is observed, beginning at some starting point $t=0$. The observation ends at time $t_{d}$, i.e. either when the event occurs, or when the observation is censored. A common choice to specify how the discrete-time hazard rate is determined, is the logistic regression function (Allison 1982: 72). If the conditional probabilities that an event occurs at time $t$, given that it has not already occurred, are sufficiently small (<.10), the logit model provides a good approximation to the continuous time proportional hazards model (Yamaguchi 1991: 18, 42).

The discrete-time logit model estimates the effect of a number of covariates on the $\log$ of the odds of an event. In the present case, the log odds that a woman experiences a first birth (second birth, respectively) within the one-year interval $t$ is

$$
\log \left[p_{i j t} /\left(1-p_{i j t}\right)\right]=b_{0}+b_{1} x_{i j}+b_{2} z_{i j t}+u_{0 j}
$$

where $p_{i j t}$ is the probability of individual $i$ in region $j$ to have a birth of a specific order in year $t, b_{0}$ is the intercept constrained to be equal across all years, $x_{i j}$ is a vector of time-constant explanatory variables, $z_{i j t}$ is a vector of time-varying explanatory variables at time $t$, and $u_{0 j}$ is the regional level random effect. Since a birth of a specific order is a non-repeatable event, no individual level unobserved heterogeneity factor can be identified.

Different from conventional logistic regression analysis, discrete-time logit models use multiple observations for each individual in the sample, i.e. each time unit during which an individual is observed contributes a separate observation to the input data. For each of these observations, the dependent variable is coded 1 if the event occurs, 0 otherwise. 


\section{Regression results}

The results of the multivariate analysis will be presented separately for first and second births. For the estimation, a strategy of stepwise inclusion of variables is applied. To begin with, a regression with just the intercept and the regional random effect is run (Model 1). In Models 2 to 4, the individual level variables are introduced. Finally, the regional level variables are added in Models 5 and 6.

For the analysis the software package $a M L$ is used (see Lillard and Panis 2000).

\section{$\underline{5.1 \text { Analysis of first births }}$}

In all models, the coefficients of the individual level control variables show the anticipated signs and are usually statistically significant where expected. Compared to women with a vocational degree, being in education strongly reduces the propensity to have a first birth. This is consistent with other studies, which also find that "women postpone childbearing until after they complete the desired amount of education." (Rindfuss et al. 1996: 279) Having a university degree, on the other hand, does not have any statistically significant impact. The positive coefficient of the dummy variable indicating that the woman terminated education without receiving any vocational or university degree looses its significance, once it is controlled for the woman's marital status (Models 4 to 6 ). Including the marital status in the analysis clearly reduces the original size of most other individual level coefficients and leads to a substantial improvement in the model's fit. As expected, the risk of married western German 
women to experience a first birth is many times higher than for the unmarried (see also Billari and Kohler 2000).

Adding regional components to the regression equation does not increase its explanatory power. Although the standard deviation of the regional random effect $\left(\sigma_{u}\right)$ in Model 2, and the coefficient of the female labour force participation (FLPR) variable in Model 6 turn out to be statistically significant at the ten per cent level, they cannot be interpreted in a substantively sensible manner. Apart from these two exceptions, neither the regional random effect, nor any of the other regional indicators exhibits a statistically significant effect on the woman's probability of having a first child. It is interesting to note, though, that the size of $\sigma_{u}$ basically remains the same in Models 1 to $3^{4}$, but decreases to almost zero, as soon as the woman's marital status is taken into account.

[Table 2 about here]

\section{$\underline{5.2 \text { Analysis of second births }}$}

Just as in the analysis of first births, the age function for the transition to the second child exhibits a concave shape. In all models, a woman's age at first birth is significantly correlated with her probability of having a second child. The positive sign of the coefficient is as expected, since a higher age at entry into parenthood allows less postponement of another birth. The same line of reasoning holds for the interpretation of

\footnotetext{
4 The small increase of $\sigma_{u}$ in Model 2 should not be interpreted as a sign of model misspecification, but rather as an expression of chance fluctuation (see Snijders and Bosker 1999: 104, 123).
} 
the educational variables (Models 3 to 6 ). Women who received a university degree are found to have a higher propensity to progress to parity two in the study period than women in the reference category, which is likely to be a 'catching-up' effect. Blossfeld and Huinink (1991: 164f.), for example, argue that "because attainment of increasing levels of education takes time and is connected with women's increasing age [...] highly qualified women [...] come increasingly under pressure", if they want to realise their fertility goals. The coefficient of the dummy variable for being in education is although large - not statistically significant, which is explained by the small number of women in the sample who are in education still (one per cent). Finally, being married strongly increases a woman's propensity to have a second birth, although the effect is somewhat smaller than for the transition to the first child.

In Model 1, the standard deviation of the regional random effect $\left(\sigma_{u}\right)$ turns out to be statistically significant, which indicates that the intercept varies over contexts. The context effect looses its significance, though, as soon as individual level control variables are entered into the regression. The size of the coefficient is reduced by about 40 per cent, even if only the individual's age, age squared, and her age at first birth are controlled for. Adding indicators of a region's degree of urbanisation (Model 5) does not lead to a statistically significant improvement of the model's fit. Living in a rural area, though, has a weakly significant effect on the woman's probability to progress to parity two, and the positive sign of the coefficient is consistent with the theoretical expectations discussed above. However, the specific impact of urbanity is immediately absorbed by the influence of the other regional indicators (Model 6), which themselves do not yield any statistically significant effect on a woman's fertility outcome during the observation period. 
[Table 3 about here]

\section{Conclusions and perspectives for future research}

In the theoretical part of this paper, it has been thoroughly discussed, how regional opportunity structures as well as local patterns of social interaction and culture may translate into parameters that directly affect individual childbearing behaviour. However, the empirical analysis performed here provides no evidence that the distinct fertility differences observed in western Germany at the regional level (Hank 2001) are due to autonomous contextual effects. The regression results rather suggest that most of the regional variation may be due to differences in the spatial distribution of individual characteristics (see also Kopp 2000).

This holds particularly for the occurrence of first births during the observation period. The fact that a woman's propensity of entering motherhood is lowest if she is in education, for example, strikingly corresponds to the observation that the lowest fertility levels in western Germany are frequently found in university towns (Hank 2001). The analysis of the transition to the second child, however, reveals at least some (weak) 'footprints' of an effect of the regional social context. This is consistent with the finding that regional fertility differences in post-war West Germany have been evident especially for higher parity births (Birg et al. 1990).

The correct specification of the context is of course a crucial matter, where researchers should seek to specify the smallest possible social units, within which the heterogeneity of institutional structures and values can be treated as negligible (Hammel 
1990: 467ff.). Thus, further research is clearly needed to investigate the influence of the choice of a specific regional social context on the empirical outcome of the analysis. Studies using Scandinavian municipality data, for instance, have revealed significant effects of the local day-care provision (Kravdal 1996) and regional employment levels (Hoem 2000) on individual fertility. For the German case, analyses referring to the district (Kreis) level may prove to be fruitful in the future. For this purpose, already existing data sources (see Hoffmeyer-Zlotnik 2000, for example) might be exploited more extensively than has been done so far. Moreover, it is hoped that regional analyses on the basis of the German micro-census (Mikrozensus) will soon be possible.

\section{References}

Alexander, J.C. / B. Giesen / R. Münch / N.J. Smelser (Eds.) (1987): The MicroMacro Link, Berkley.

Allison, P.A. (1982): Discrete-Time Methods for the Analysis of Event Histories, in: S. Leinhardt (Ed.), Social Methodology, San Francisco, pp.61-98.

Alker, H.R. (1969): A typology of ecological fallacies, in: M. Dogan / S. Rokkan (Eds.), Quantitative Ecological Analysis in the Social Sciences, Cambridge, pp. 69-86.

Andorka, R. (1978): Determinants of Fertility in Advanced Societies, London.

Billari, F. / H.-P. Kohler (2000): The impact of union formation dynamics on first births in West Germany and Italy: are there signs of convergence?, MPIDR Working Paper WP 2000-008, Rostock.

Billy, J.O. / D.E. Moore (1992): A multilevel analysis of marital and nonmarital fertility in the U.S., in: Social Forces, 70, pp.977-1011.

Birg, H. / D. Filip / E.-J. Flöthmann (1990): Paritätsspezifische Kohortenanalyse des generativen Verhaltens in der Bundesrepublik Deutschland nach dem 2. Weltkrieg, IBS-Materialien No.30, Bielefeld.

Blalock, H.M. (1984): Contextual-Effects Models: Theoretical and Methodological 
Issues, in: Annual Review of Sociology, 10, pp.353-372..

Blossfeld, H.-P. (1987): Labor-Market Entry and the Sexual Segregation of Careers in the Federal Republic of Germany, in: American Journal of Sociology, 93, pp.89-118.

Blossfeld, H.-P. / J. Huinink (1991): Human Capital Investments or Norms of Role Transition? How Women's Schooling and Career Affect the Process of Family Formation, in: American Journal of Sociology, 97, pp.143-168.

Bongaarts, J. / S.C. Watkins (1996): Social Interactions and Contemporary Fertility Transitions, in: Population and Development Review, 22, pp.639-683.

Brewster, K.L. / R.R. Rindfuss (2000): Fertility and Women's Employment in Industrialized Nations, in: Annual Review of Sociology, 26, pp.271-296.

Brunetta, G. / G. Rotondi (1991): Urban and rural fertility in Italy: Regional and temporal changes, in: J. Bähr / P. Gans (Eds.), The Geographical Approach to Fertility, Kieler Geographische Schriften, Vol. 78, Kiel, pp.203-218.

Bundesamt für Bauwesen und Raumordnung (BBR) (1999): Aktuelle Daten zur Entwicklung der Städte, Kreise und Gemeinden, Berichte - Vol. 3, Bonn.

Campbell, E.Q. / C.N. Alexander (1965): Structural Effects and Interpersonal Relationships, in: American Journal of Sociology, 71, pp.284-289.

Coale, A.J. / S.C. Watkins (Eds.) (1986): The Decline of Fertility in Europe, Princeton.

Coleman, J.S. (1990): Foundations of Social Theory, Cambridge.

Conrad, C. / M. Lechner / W. Werner (1996): East German Fertility After Unification: Crisis or Adaptation?, in: Population and Development Review, 22, pp.331-358.

Courgeau, D. / B. Baccaini (1998): Multilevel Analysis in the Social Sciences, in: Population (English Selection), 10, pp.39-71.

De Cooman, E. / J. Ermisch / H. Joshi (1987): The next birth and the labour market. A dynamic model of births in England and Wales, in: Population Studies, 41, pp.237-268.

DiPrete, T.A. / J.D. Forristal (1994): Multilevel Models - Methods and Substance, in: Annual Review of Sociology, 20, pp.331-357.

Entwisle, B. (1991): Micro-Macro Theoretical Linkages in Social Demography: A Commentary, in: J. Huber (Ed.), Macro-Micro Linkages in Sociology, Newbury Park, pp.280-286.

Entwisle, B. / J.B. Casterline / H.A.-A. Sayed (1989): Villages as Contexts for 
Contraceptive Behavior in Rural Egypt, in: American Sociological Review, 54, pp.1019-1034.

Erbring, L. / A.A. Young (1979): Individuals and Social Structure. Contextual Effects as Endogenous Feedback, in: Sociological Methods \& Research, 7, pp.396-430.

Esser, H. (1988): Sozialökologische Stadtforschung und Mehr-Ebenen-Analyse, in: J. Friedrichs (Ed.), Soziologische Stadtforschung, Kölner Zeitschrift für Soziologie und Sozialpsychologie, Sonderheft 29, Opladen, pp.33-55.

Evans, W.N. / W.E. Oates / R.M. Schwab (1992): Measuring Peer Group Effects: A Study of Teenage Behavior, in: Journal of Political Economy, 100, pp.966-991.

Falter, J.W. (1978): Some theoretical and methodological problems of multilevel analysis reconsidered, in: Social Science Information, 17, pp.841-869.

Ginther, D. / R. Haveman / B. Wolfe (2000): Neighborhood Attributes as Determinants of Children's Outcomes, in: The Journal of Human Resources, 35 , pp.603-642.

Guo, G. / Zhao, H. (2000): Multilevel Modeling for Binary Data, in: Annual Review of Sociology, 26, pp.441-462.

Hammel, E.A. (1990): A Theory of Culture for Demography, in: Population and Development Review, 16, pp.455-485.

Hank, K. (2001): Regional Fertility Differences in Western Germany. An Overview of the Literature and Recent Descriptive Findings, mimeo, MPIDR, Rostock.

Hank, K. / M. Kreyenfeld (2001): Childcare and Fertility in (Western) Germany, Paper prepared for the Jahrestagung der Deutschen Gesellschaft für Demographie, Berlin, June 21-23.

Hauser, R.M. (1974): Contextual Analysis Revisited, in: Sociological Methods \& Research, 2, pp.365-375.

Hirschman, C. / P. Guest (1990): Multilevel Models of Fertility Determination in Four Southeast Asian Countries: 1970 and 1980, in: Demography, 27, pp.369396.

Hoem, B. (2000): Entry into motherhood in Sweden: the influence of economic factors on the rise and fall in fertility, 1986-1997, in: Demographic Research [Online] 2, available www.demographic-research.org/Volumes/Vol2/4.

Hoffmeyer-Zlotnik, J.H.P. (2000): Methodische Aspekte der Anwendung regionaler Stichproben, in: H. Bertram et al. (Eds.), Solidarität, Lebensformen und regionale Entwicklung, Opladen, pp.313-343.

Höpflinger, F. (1983): Regionale Unterschiede der Geburtenhäufigkeit in der 
Schweiz, in: Akademie für Raumforschung und Landesplanung (Ed.), Regionale Aspekte der Bevölkerungsentwicklung unter den Bedingungen des Geburtenrückgangs, Forschungs- und Sitzungsberichte, Vol. 144, Hannover, pp.67-80.

Hox, J.J. / I.G.G. Kreft (1994): Multilevel Analysis Models, in: Sociological Methods \& Research, 22, pp.283-299.

Huber, J. (1991) (Ed.): Macro-Micro Linkages in Sociology, Newbury Park

Huckfeldt, R.R. (1983): Social Contexts, Social Networks, and Urban Neighborhoods: Environmental Constraints on Friendship Choice, in: American Journal of Sociology, 89, pp.651-669.

Huinink, J. / M. Wagner (1989): Regionale Lebensbedingungen, Migration und Familienbildung, in: Kölner Zeitschrift für Soziologie und Sozialpsychologie, 41, pp.669-689.

Iversen, G.R. (1991): Contextual Analysis, Newbury Park.

Jencks, C. / S.E. Mayer (1990): The Social Consequences of Growing Up in a Poor Neighborhood, in: L.E. Lynn / M.G.H. McGeary (Eds.), Inner-City Poverty in the United States, Washington, pp.111-186.

Kopp, J. (2000): Geburtenentwicklung in Ost- und Westdeutschland, in: H. Bertram et al. (Eds.), Solidarität, Lebensformen und regionale Entwicklung, Opladen, pp.83-135.

Kravdal, Ø. (1996): How the local supply of day-care centers influences fertility in Norway: A parity-specific approach, in: Population Research and Policy Review, 15, pp.201-218

Kreft, I. / J. de Leeuw (1998): Introducing Multilevel Modeling, London.

Kreyenfeld, M. / K. Hank (2000): Does the availability of child care influence the employment of mothers? Findings from western Germany, in: Population Research and Policy Review, 19, pp.317-337.

Kutzenberger, K. / E. Fürst (1983): Die regionalen Unterschiede der Geburtenhäufigkeit in Oberösterreich (1969-1978), in: Akademie für Raumforschung und Landesplanung (Ed.), Regionale Aspekte der Bevölkerungsentwicklung unter den Bedingungen des Geburtenrückgangs, Forschungs- und Sitzungsberichte, Vol. 144, Hannover, pp.51-66.

Lillard, L.A. / C.W.A. Panis (2000): aML Multilevel Multiprocess Statistical Software, Release 1.0, EconWare, Los Angeles.

Manski, C.F. (1993): Identification of Endogenous Social Effects: The Reflection Problem, in: Review of Economic Studies, 60, pp..531-542. 
Montgomery, M.R. / J.B. Casterline (1996): Social Learning, Social Influence, and New Models of Fertility, in: J.B. Casterline et al. (Eds.), Fertility in the United States: New patterns, New Theories, Supplement to Population and Development Review, 22, pp.151-75.

Moulton, B.R. (1990): An Illustration of a Pitfall in Estimating the Effects of Aggregate Variables on Micro Units, in: The Review of Economics and Statistics, 32, pp.334-338.

Nauck, B. (1995): Regionale Millieus von Familien in Deutschland nach der politischen Vereinigung, in: B. Nauck / C. Onnen-Isemann (Eds.), Familie im Brennpunkt, Neuwied, pp. 91-121.

Noin, D. / Y. Chauviré (1991): The geographical disparities of fertility in France, in: J. Bähr / P. Gans (Eds.), The Geographical Approach to Fertility, Kieler Geographische Schriften, Vol. 78, Kiel, pp.151-164.

Rindfuss, R.R. / S.P. Morgan / K. Offutt (1996): Education and the Changing Pattern of American Fertility: 1963-1989, in: Demography, 33, pp.277-290.

Snijders, T.A.B. / R.J. Bosker (1999): Multilevel analysis: An introduction to basic and advanced multilevel modeling, London.

Stolzenberg, R.M. / L.J. Waite (1984): Local Labor Markets, Children and Labor Force Participation of Wives, in: Demography, 21, pp.157-170.

Strohmeier, K.-P. (1989): "Movers" und "Stayers". Räumliche Mobilität und Familienentwicklung, in: A. Herlth / K.-P. Strohmeier (Eds.), Lebenslauf und Familienentwicklung, Opladen, pp.165-188.

Van de Kaa, D. (1987): Europe's Second Demographic Transition, Population Bulletin, 42, Washington.

Wagner, G. / R.V. Burkhauser / F. Behringer (1993): The English Language Public Use File of the German Socio-Economic Panel Study, in: The Journal of Human Resources, 28, pp.429-433.

Westoff, C.F. (1999): Mass Communications and Fertility, in: R. Leete (Ed.), Dynamics of Values in Fertility Change, Oxford, pp.237-251.

Yamaguchi, K. (1991): Event History Analysis, Newbury Park. 


\section{Appendix}

Table 1: Descriptive sample statistics - First and second births, 1984 to 1995

\begin{tabular}{|c|c|c|}
\hline & $\begin{array}{c}\text { First birth } \\
\text { Mean }(\text { Stdv. })^{\text {a) }}\end{array}$ & $\begin{array}{l}\text { Second birth } \\
\text { Mean }(\text { Stdv. })^{\text {a) }}\end{array}$ \\
\hline Number of births & 836 & 532 \\
\hline $\begin{array}{l}\text { Individual level } \\
\text { Age }\end{array}$ & $25.1(4.0)$ & $31.8(4.4)$ \\
\hline Age squared & $648.5(212.2)$ & $1030.9(287.4)$ \\
\hline Age at first birth & - & $25.0(4.1)$ \\
\hline In education & .17 & .01 \\
\hline No degree & .18 & .24 \\
\hline Vocational degree & .57 & .68 \\
\hline University degree & .07 & .06 \\
\hline Marital status & .28 & .82 \\
\hline Foreigner & .23 & .24 \\
\hline $\begin{array}{l}\text { Regional level }^{\mathrm{b})} \\
\text { Agglomeration }\end{array}$ & .62 & .62 \\
\hline Urbanised area & .26 & .26 \\
\hline Rural area & .12 & .12 \\
\hline $\begin{array}{l}\text { Day-care provision (\# of slots per } \\
1000 \text { children aged } 3 \text { to } 6 \text { ) }\end{array}$ & $829.2(162.0)$ & $831.8(164.1)$ \\
\hline Tertiary sector (in per cent) & $52.5(8.4)$ & $52.1(8.7)$ \\
\hline Unemployment rate (in per cent) & $8.1(3.0)$ & $8.1(3.0)$ \\
\hline $\begin{array}{l}\text { Female labour force participation } \\
\text { rate (FLPR) (in per cent) }\end{array}$ & $42.1(6.5)$ & $42.1(6.6)$ \\
\hline $\begin{array}{l}\mathrm{N} \text { (regions) } \\
\mathrm{N} \text { (women) } \\
\mathrm{N} \text { (spells) }\end{array}$ & $\begin{array}{c}75 \\
2,474 \\
10,451\end{array}$ & $\begin{array}{c}75 \\
1,316 \\
4,867\end{array}$ \\
\hline \multicolumn{3}{|c|}{$\begin{array}{l}\text { Note: } \\
\text { a) Standard deviations are not displayed for binary variables. } \\
\text { b) Minor differences in the mean values of some of the regional level variables for first } \\
\text { and second births are due to a slightly different distribution of the individuals across } \\
\text { Raumordnungsregionen. }\end{array}$} \\
\hline
\end{tabular}

Source: GSOEP and GSOEP-Geocode 1984-1995, author's calculations 
Table 2: Results of multilevel discrete-time logit models for the dependent variable 'first birth', 1984 to 1995

\begin{tabular}{|c|c|c|c|c|c|c|c|c|c|c|c|c|c|c|c|c|c|c|}
\hline & & lel 1 & & & odel 2 & & & del 3 & & & odel 4 & & & odel 5 & & & del 6 & \\
\hline & $\beta$ & s.e. & Sig. & $\beta$ & s.e. & Sig. & $\beta$ & s.e. & Sig. & $\beta$ & s.e. & Sig. & $\beta$ & s.e. & Sig. & $\beta$ & s.e. & Sig. \\
\hline Age & - & & & .98 & .11 & $* * *$ & .80 & .11 & $* * *$ & .42 & .12 & $* * *$ & .43 & .12 & $* * *$ & .43 & .14 & $* * *$ \\
\hline Age squared & - & & & -.02 & .00 & $* * *$ & -.01 & .00 & $* * *$ & -.01 & .00 & $* * *$ & -.01 & .00 & $* * *$ & -.01 & .00 & $* * *$ \\
\hline In education ${ }^{\text {a) }}$ & - & & & - & & & -1.52 & .22 & $* * *$ & -.77 & .22 & $* * *$ & -.77 & .23 & $* * *$ & -.77 & .25 & $* * *$ \\
\hline No degree ${ }^{a)}$ & - & & & - & & & .23 & .09 & $* * *$ & .03 & .11 & & .03 & .11 & & .03 & .13 & \\
\hline University degree $^{\text {a) }}$ & - & & & - & & & -.08 & .17 & & .22 & .19 & & .23 & .19 & & .25 & .20 & \\
\hline Marital status & - & & & - & & & - & & & 2.64 & .12 & $* * *$ & 2.64 & .12 & $* * *$ & 2.66 & .12 & $* * *$ \\
\hline Foreigner & - & & & - & & & - & & & .12 & .12 & & .12 & .12 & & .10 & .13 & \\
\hline Urbanised area $^{\text {b) }}$ & - & & & - & & & - & & & - & & & .12 & .10 & & .18 & .12 & \\
\hline Rural area ${ }^{\text {b) }}$ & - & & & - & & & - & & & - & & & .04 & .14 & & .01 & .18 & \\
\hline Childcare & - & & & - & & & - & & & - & & & - & & & .00 & .00 & \\
\hline Tertiary sector & - & & & - & & & - & & & - & & & - & & & -.01 & .01 & \\
\hline Unemployment & - & & & - & & & - & & & - & & & - & & & .02 & .03 & \\
\hline FLPR & - & & & - & & & - & & & - & & & - & & & .02 & .01 & $*$ \\
\hline Constant & -2.44 & .04 & $* * *$ & -15.92 & 1.43 & $* * *$ & -13.18 & 1.43 & $* * *$ & -8.73 & 1.53 & $* * *$ & -8.83 & 1.61 & $* * *$ & -8.99 & 1.95 & $* * *$ \\
\hline$\sigma_{u}$ & .12 & .08 & & .14 & .08 & $*$ & .14 & .09 & & .01 & .87 & & .00 & - & & .00 & - & \\
\hline-2 Log likelihood ${ }^{c}$ & 5825 & & - & 5728 & & $* * *$ & 5610 & & $* * *$ & 4624 & & $* * *$ & 4622 & & & 4615 & & \\
\hline $\begin{array}{l}\text { Note: } \\
\text { a) Reference categor } \\
\text { b) Reference categor } \\
\text { c) Significance test } \mathrm{f} \\
\text { Significance: } *<.10\end{array}$ & $\begin{array}{l}\text { ational } \\
\text { lomera } \\
\text { og lik } \\
5 ; * * *\end{array}$ & $\begin{array}{l}\text { gree. } \\
\text { hood } \\
1\end{array}$ & npar & o the $\mathrm{p}$ & jious 1 & & & & & & & & & & & & & \\
\hline
\end{tabular}

Source: GSOEP and GSOEP-Geocode 1984-1995, author's calculations 
Table 3: Results of multilevel discrete-time logit models for the dependent variable 'second birth', 1984 to 1995

\begin{tabular}{|c|c|c|c|c|c|c|c|c|c|c|c|c|c|c|c|c|c|c|}
\hline & \multicolumn{3}{|c|}{ Model 1} & \multicolumn{3}{|c|}{ Model 2} & \multicolumn{3}{|c|}{ Model 3} & \multicolumn{3}{|c|}{ Model 4} & \multicolumn{3}{|c|}{ Model 5} & \multicolumn{3}{|c|}{ Model 6} \\
\hline & $\beta$ & s.e. & Sig. & $\beta$ & s.e. & Sig. & $\beta$ & s.e. & Sig. & $\beta$ & s.e. & Sig. & $\beta$ & s.e. & Sig. & $\beta$ & s.e. & Sig. \\
\hline Age & - & & & .63 & .22 & $* * *$ & .57 & .24 & $* *$ & .63 & .24 & $* *$ & .63 & .25 & $* *$ & .62 & .24 & $* *$ \\
\hline Age squared & - & & & -.01 & .00 & $* * *$ & -.01 & .00 & $* * *$ & -.01 & .00 & $* * *$ & -.01 & .00 & $* * *$ & -.01 & .00 & $* * *$ \\
\hline Age at $1^{\text {st }}$ birth & - & & & .12 & .02 & $* * *$ & .12 & .02 & $* * *$ & .09 & .02 & $* * *$ & .09 & .02 & $* * *$ & .09 & .02 & $* * *$ \\
\hline In education $^{\text {a) }}$ & - & & & - & & & -1.75 & 1.23 & & -1.48 & 1.31 & & -1.48 & 1.31 & & -1.45 & 1.36 & \\
\hline No degree $e^{a)}$ & - & & & - & & & .04 & .13 & & .04 & .15 & & .04 & .15 & & .04 & .16 & \\
\hline University degree $^{\text {a) }}$ & - & & & - & & & .64 & .18 & $* * *$ & .66 & .18 & $* * *$ & .67 & .19 & $* * *$ & .66 & .20 & $* * *$ \\
\hline Marital status & - & & & - & & & - & & & 1.55 & .27 & $* * *$ & 1.56 & .28 & $* * *$ & 1.56 & .29 & $* * *$ \\
\hline Foreigner & - & & & - & & & - & & & .09 & .16 & & .11 & .17 & & .08 & .18 & \\
\hline Urbanised area ${ }^{\text {b) }}$ & - & & & - & & & - & & & - & & & -.02 & .17 & & -.04 & .17 & \\
\hline Rural area ${ }^{\text {b) }}$ & - & & & - & & & - & & & - & & & .27 & .16 & $*$ & .24 & .17 & \\
\hline Childcare & - & & & - & & & - & & & - & & & - & & & .00 & .00 & \\
\hline Tertiary sector & - & & & - & & & - & & & - & & & - & & & .00 & .00 & \\
\hline Unemployment & - & & & - & & & - & & & - & & & - & & & -.01 & .03 & \\
\hline FLPR & - & & & - & & & - & & & - & & & - & & & .00 & .01 & \\
\hline Constant & -2.11 & .06 & $* * *$ & -12.32 & 3.44 & $* * *$ & -11.21 & 3.70 & $* * *$ & -13.15 & 3.80 & $* * *$ & -13.31 & 3.80 & $* * *$ & -13.43 & 4.00 & $* * *$ \\
\hline$\sigma_{u}$ & .21 & .07 & $* * *$ & .13 & .10 & & .11 & .11 & & .09 & .15 & & .08 & .16 & & .00 & - & \\
\hline -2 Log likelihood ${ }^{\mathrm{c}}$ & 3354 & - & & 3137 & & $* * *$ & 3117 & & & 3046 & & $* * *$ & 3042 & & & 3040 & & \\
\hline $\begin{array}{l}\text { Note: } \\
\text { a) Reference categor } \\
\text { b) Reference categor } \\
\text { c) Significance test } \mathrm{f} \\
\text { Significance: } *<10\end{array}$ & $\begin{array}{l}\text { ational } \\
\text { lomera } \\
\text { Log lik } \\
05 ; * * *\end{array}$ & $\begin{array}{l}\text { n. } \\
\text { hood } \\
01\end{array}$ & mpare & to the pr & vious & & & & & & & & & & & & & \\
\hline
\end{tabular}

Source: GSOEP and GSOEP-Geocode 1984-1995, author's calculations 